\title{
Neuropsychiatric manifestations of bromide ingestion
}

\author{
DAVID G. J. BATTIN \\ M.B., Ch.B., M.R.C.Psych. \\ T. ANTONY VARKEY \\ M.B., B.S.
}

Worcester Royal Infirmary, (Newtown Branch), Newtown Road, Worcester

\begin{abstract}
Summary
Two cases of bromide intoxication are reported. Although the serum bromide levels were not particularly high, they were related to typical neurological and psychiatric features of bromism. The authors wish to suggest that the rare syndrome of bromism be considered in the differential diagnosis of obscure or refractory neuro-psychiatric symptomatology.
\end{abstract}

\section{Introduction}

Bromides were formerly used for their sedative and anti-convulsant properties. The neuropsychiatric features of bromide intoxication have been recognized for many years (Barbour, Pilkington and Sargent, 1936). Carney (1971) described 5 cases of bromism and advocated stricter control on bromide preparations. Part III of the Medicine Act (1978) made potassium bromide available only by prescription. Bromides have been almost completely replaced by more effective and less toxic agents, and consequently bromide intoxication is now rare. However, there is evidence that it is under-diagnosed (Williams, 1974). We would like to report two cases of bromism seen over an 18-month period at a general hospital psychiatric unit. Bromide levels were measured by a modification of the method of Sunshine (1971).

\section{Case 1}

A 77-year-old man, a retired industrial chemist of eccentric schizoid personality, was admitted having thrown a brick through a neighbour's greenhouse. He complained that over the previous four weeks he had experienced intermittent tingling in his legs, associated with the hallucinatory experience of movements of his house, which he ascribed to electricity being passed through cables from his neighbour's house. He also mentioned being aware of an unpleasant smelling gas in the house. On examination, he was garrulous, and incongruously euphoric in mood. He was fully orientated and had a good memory. Psychometric testing showed an IQ of 120 , with no intellectual impairment. Physical examination revealed a fine finger tremor, a wide-based unsteady gait, normal reflexes, flexor plantar responses and no sensory loss. He later described taking a teaspoonful of potassium bromide granules in water at least once a week for the last 30 years. Serum bromide estimation nearly 3 weeks after admission was 400 $\mathrm{mg} / \mathrm{litre}$. A paranoid psychosis associated with bromism was diagnosed, and he was treated with oral chlorpromazine, $300 \mathrm{mg}$ per day for a week, and followed by fluphenazine decanoate injections $25 \mathrm{mg}$ every 2 weeks for 3 months. Gradually his psychotic symptoms and general physical state improved, and he was discharged to a nursing home. In this setting his serum bromide levels have been zero and he remains well.

\section{Case 2}

A 53-year-old nursing sister was referred for admission by her general practitioner, with an 18month history of a variable degree of depression of mood, drowsiness, and mild memory impairment. No sleep disturbance, weight-loss or appetite changes were reported. Several types of anti-depressant medication had been tried, with no significant benefit, and full assessment in a neurological unit had demonstrated no cause for her symptoms. On admission, she was found to have dysarthria, a fine finger tremor, an unsteady gait, and bilateral extensor plantar responses. There was no rash. Investigation revealed a serum bromide level of $310 \mathrm{mg}$ per litre, which fell to zero after one week with complete resolution of her mental and neurological symptoms. Psychometric assessment demonstrated no significant intellectual or memory impairment. The only medication that she would admit to taking was atenolol $50 \mathrm{mg}$ daily for long-standing well-controlled hypertension. She could offer no explanation for the raised bromide level. During out-patient follow-up she remained asymptomatic except for one occasion, when she was dysarthric and ataxic at which time her serum bromide level was $250 \mathrm{mg} / \mathrm{litre}$. 


\section{Discussion}

Bromides are rapidly absorbed orally and distributed throughout the body in competition with chlorides. Excretion is primarily by the kidneys, with a half-life of about 12 days (Torosian, Finger \& Stewart, 1973). Any condition which interferes with an adequate intake of food or salt will predispose to bromide intoxication. Both the reported patients were poorly nourished for several months before admission. The blood bromide level is a rough index to the degree of intoxication, though individual susceptibility varies greatly, and following prolonged bromide intoxication, the serum levels may not accurately reflect the nervous system involvement (Whybrow \& Ewing, 1966). Mental disturbance is usually considered very likely to occur when blood bromide level exceeds $100 \mathrm{mg} / \mathrm{dl}$ (Barbour et al., 1936), but toxic effects may depend more on the general mental state, premorbid personality, duration of ingestion, state of hydration, and electrolyte balance of the patient (Freedman, Kaplan \& Sadack, 1978). Blood levels measured in our cases are lower than some of those quoted in the literature, but the elevated levels seemed to correlate well with the morbid features of bromism. Other cases with similar serum bromide levels have been reported (Sayed, 1976; Gerner, 1978).

The two main clinical syndromes associated with bromide ingestion are (1) intoxication, where there is clouding of consciousness, associated with dysarthria, ursteadiness of gait, dysmnesia, mood disturbance and perceptual distortions, (2) schizophreniform psychosis, where paranoid delusions and hallucinations develop acutely in clear consciousness in people of schizoid propensities (Levin, 1951). Our cases appear to be examples of both types of syndromes.

The sources of bromides for both patients have not been determined. In the first case, the bottles of granules of potassium bromide may have been obtained before the change of law in 1978, as it was then sold as a component of home-made photo- graphic developer. A thorough search of their house by the husband of the second patient revealed no $\mathbb{D}$ source of bromides. There is no evidence that either $c$ patient was obtaining bromides by prescription from a local medical practitioner. It is unlikely that drugs $\stackrel{5}{\rightarrow}$ other than sodium and potassium bromide wouldo cause clinically significant serum bromide levels. 흘 Therapeutic doses of emepronium bromide, for $\frac{\bar{\sigma}}{\sigma}$ example, give maximum serum levels of $800 \mathrm{ng} / \mathrm{ml} \stackrel{\mathbb{}}{\propto}$ (Wade, 1977).

We suggest that bromide intoxication be considered in the differential diagnosis of obscure, unusual $\vec{\circ}$ or refractory psychiatric symptomatology.

\section{Acknowledgments}

We thank Dr P. Hall, Consultant Psychiatrist, for permission to report these cases, and Mrs C. G. Kellett, Hospital Pharmacist, and ${ }^{\circ}$ Miss J. Haidon, our team Secretary, for their assistance in preparing $N$ this paper.

\section{References}

Barbour, R.F., Pilkington, F. \& Sargent, W. (1936) Bromide Intoxication. British Medical Journal, 2, 957.

CARNEY, M.W.P. (1971) Five cases of bromism. Lancet, ii, 523.

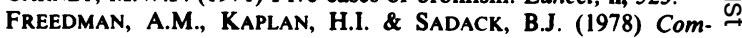
prehensive Text Book of Psychiatry, Vol. 12nd edn, pp. 1110-11 8 William and Wilkins, Baltimore.

GERNER, R.H. (1978) Bromism from over-the-counter medication American Journal of Psychiatry, 135, 1428.

LEVIN, M. (1951) Experimental bromide intoxication, a criticism American Journal of Psychiatry, 108, 309.

SAYED, A.J. (1976) Mania and bromism. American Journal of Psychiatry, 133, 228.

SUNSHINE, L. (1971) Manual of Analytical Toxicology, p. 58. C.R.P. Ф Press.

TOROSIAN, G., Finger, K.F. \& STEWART, R.B. (1973) Hazards of $\overrightarrow{\bar{O}}$ bromides in proprietory medications. American Journal of Hospi- 3 tal Pharmacy, 30, 716.

WADE, A. (Ed.) (1977) Martindale. The Extra Pharmacopoeia, 27th edn. The Pharmaceutical Press, London.

WHYBROW, P.C. \& EWING, J.A. (1966) Self perpetuation of bromism. British Medical Journal, 2, 886.

WILlIAMS, R.J. (1974) Organic psychosis. British Medical Journal, 3, 629. 